\title{
O DIREITO COMPARADO
}

LUIZ FERNANDO COELHO

Professor de Introdução ao Estudo do Direito nas Universidades Federal e Católica do Paraná.

Sumário: - 1. Condições de existência do Direito Comparado. 2. Conceito e objeto do Direito Comparado. 3. Fatores de diversificação e de nivelamento dos sistemas jurídicos. 4. Repercussões do Direito Comparado na Ciência do Direito. 5. A classificação dos sistemas jurídicos.

1. Entre as ciências jurídicas, merece um destaque especial o Direito Comparado, pelo significado que assume na época atual como fator de universalização da Jurisprudência. Representa um dos esforços mais profícuos para suprir as consequências negativas decorrentes da nacionalização dos ordenamentos jurídicos, fenômeno que ocorreu de maneira crescente após o movimento de codificação, quando os sistemas de Direito Positivo do mundo ocidental, erigidos em objeto primordial da Ciência do Direito, induziram os juristas a uma ten. dência quase viciosa a considerar esta como uma ordem de conhecimentos divididos em tantos compartimentos quantos fossem os países existentes, separados entre si pelas fronteiras políticas dos Estados. Tal compartimentação é produto dos tempos modernos. Epo. ca houve em que os conhecimentos jurídicos tinham o mesmo foro de universalidade quanto os de qualquer outra ordem científica ou filosófica. Foi à época em que as instituições romanas, pela superioridade técnica, se impunham ao direito costumeiro da Europa ocidental. Embora se tratasse de direito romano, portanto, referido a um povo e a um Estado, não se cogitava de limitações geográficas ou política em relação ao estudo científico de suas instituições, do mesmo modo que o estudo da Filosofia grega não circunscrevia a Filosofia à nação e ao Estado gregos. Idêntica universalidade ocorria no mundo medieval quando o direito canônico unia os inumeráveis 
Estados feudais sob um único ordenamento, em relação a diversas questões, e também à época pré-renascentista, quando o direito romano redescoberto era ensinado nas primeiras universidades e se constifuía em autêntico jus commune, pela obra dos glosadores e pósglosadores.

Após a promulgação do Código de Napoleão e sob a égide das escolas exegéticas que se the seguiram, o Direito Positivo e a própria Jurisprudência começaram a ressentir-se desse processo crescente de compartimentação segundo as fronteiras geo-políticas. Tal fenômeno pode ser observado no simples fato de que os profissionais do Direito, pelo menos advogados e magistrados, não possuem condições de exercício de sua profissão fora de seu país; isto ocorreria ainda que por hipótese viesse a ser permitido. Além disso, muito dificilmente o jurisconsulto de um país, considerado cientista do direito entre os seus, poderia prelecionar a sua disciplina jurídica em Universidade estrangeira, como acontecia no passado. Tal não ocorre com outras ciências, pois sociólogos, economistas, filósofos, biólogos, matemáticos, etc., sentem-se perfeitamente à vontade para prelecionar as respectivas disciplinas em quaisquer instituições, independentemente do país onde estejam situadas, contanto, evidentemente, que sejam superadas as barreiras linguísticas. Um outro fator pode ser acrescido para explicar a perda de unidade da jurisprudência; trata-se da diminuição do valor dos estudos de Filosofia do Direito, a eliminação dessa disciplina dos currículos dos cursos jurídicos ou a sua redução qualitativa e quantitativa no conjunto das disciplinas jurídicas, fato esse agravado pela perda do rumo dos fundamentos do Direito; na Ciência Jurídica desenvolvida após as grandes codificações, a Filosofia do Direito era o último baluarte da universalidade do Direito (').

A Ciência Jurídica contemporânea tomou consciência desse fato, na doutrina e na prática, em parte devido ao incremento das relações internacionais, e também pelo progresso dos estudos de Epistemologia Jurídica; assim é que ressurge com maior vigor a antiga ambição de tornar a Jurisprudência tão universal quanto as outras ciências, mesmo a despeito de as instituições jurídico-positivas se aterem cada vez mais aos respectivos povos e nações; muito embora - estabelecimento de uma Ordem Jurídica universalmente válida esteja cada vez mais relegado à utopia, a pretensão dos atuais cientistas do direito em conduzir a sua ciência à universalidade, além de legítima possui os seus fundamentos científicos, os quais a Episte-

(1) Sobre a separação entre a Jurisprudência e a Filosofia do Direito, v. Miguel Reale, 0 Direito como Experiência, Saraiva, São Paulo, 1968, pág. 75 e segs. 
mologia Jurídica, no campo da Filosofia do Direito, e o Direito Comparado, no âmbito da Jurisprudência, buscam sistematizar.

O ponto de partida é o fato de que o Estado não é mais do que um acidente histórico, durável sem dúvida, porém mutável de acordo com as influências ecológicas, demográficas, econômicas e de ordem subjetiva $\left({ }^{2}\right)$ que o condicionam e que condicionam a Ordem Jurídica; mais ainda, parte-se de uma constatação elementar, a de que os homens, com o progresso da civilização, com o aperfeiçoamento dos meios de comunicação e a maior complexidade das relações sociais, estão a exigir grupamentos mais amplos aos quais as nossas fórmulas de legalidade estatal não mais se enquadram; isso gera uma tendência a ocorrer um hiato cada vez mais acentuado entre a realidade jurídica e as fórmulas de legalidade que, por força do poder político conservador, procuram manter-se, isto é, a inadequação entre a vivência do direito e a sua forma, entre a norma e sua matéria, entre a conduta e sua expressão normativa, entre os modelos jurídicos e a matéria social; eis um aspecto da crise do Direito, no dizer de Orlando Gomes $\left({ }^{3}\right)$.

Sendo o Direito Comparado a mais jovem das disciplinas jurídicas, muito existe a construir, o que traduz um vasto campo de pesquisas ao jurista especialmente vocacionado. Pelo que já se tem feito, graças ao trabalho de inúmeros Institutos de Direito Comparado, podem-se distinguir algumas das noções fundamentais a nóvel disciplina (4).

2. O objeto do Direito Comparado releva da dialética confrontação entre situações reguladas por diferentes sistemas normativos; ele extravasa a "Legislação Comparada", entendida como confrontação, aproximação, cotejo ou mesmo comparação de instituições jurídicas de Estados diferentes, com o fito de anotar suas discrepâncias e determinar as analogias encontradas, com vistas à aproximação ou reconciliação das legislações diferentes $\left({ }^{5}\right)$, ou objetivando a solução de um contencioso onde as fontes tradicionais do Direito local sejam

(2) Sobre o Estado como fenômeno histórico, v. Giorgio Balladore Pallieri, A Doutrina do Estado, trad. de Fernando de Miranda, Coimbra, 1969. Sobre os fatores de formação e evolução do direito, José Saraiva, Lições de Introdução ao Direito, Curso professado no Instituto Superior de Ciências Sociais e Política Ultramarina da Universidade Técnica de Lisboa, 1962-1963.

(3) Orlando Gomes, A Crise do Direito, São Paulo, 1955.

(4) Entre as instituições dedicadas ao Direito Comparado destaca-se a Association Internationale de Droit Comparé, com sede em Estrasburgo, mantenedora da Faculté International pour I'Enseignement du Droit Comparé, que reúne em seu corpo docente os comparatistas mais eminentes da atualidade. Sobre essas instituições, v. René David, Les Grands Systemes de Droit Contemporains, Paris, 1964, págs. 601 e segs.

(5) De Plácido e Silva, Vocabulário Jurídico, verbete "Direito Comparado". 
consideradas insuficientes para o dirimir; o Direito Comparado é muito mais amplo; o seu objeto é constituído pelo conjunto das fontes do Direito, com a finalidade de descobrir as constantes de sua evolução; e assim a disciplina se afirma com foros de autonomia científica $\left.{ }^{6}\right)$, pois, não se restringindo à mera contemplação e descrição dos ordenamentos estrangeiros, pretende estabelecer um relacionamento entre as correntes do pensamento e as regras de Direito com as práticas judiciais e extra-judiciais, e reconstituir as relações dos diversos institutos entre si naquilo que elas possuem de perene, assim como as suas relações com a política geral dos povos e com os grandes agrupamentos humanos; este largo objetivo envolve considerações de natureza sociológica, econômica, histórica e filosófica, e não somente técnico-jurídicas e políticas. Não obstante, afasta-se o risco de enciclopedismo, pois as contribuições das diferentes ciências jurídicas e algumas não jurídicas são reunidas sob idêntico ponto de vista formal, qual seja, o da própria jurisprudência, isto é, a redução de todos os diferentes conhecimentos oriundos daquelas ordens científicas a uma expressão de positividade normativa. Malgrado a identificação de seu objeto formal com o da Jurisprudência, não fica afastado o risco de confusão com outras ciências, sociais e culturais, em especial as que, tal como o Direito Comparado, são produto do pensamento contemporâneo; refiro-me à Política e a algumas disciplinas jurídicas que tendem à autonomia científica, mercê do considerável desenvolvimento de seus estudos, entre as quais a Teoria do Estado. A dificuldade maior está em que, para estas três ordens de conhecimento, a Política, a Teoria do Estado e o Direito Comparado, o campo de trabalho e respectivos métodos de pesquisa não estão suficientemente definidos, motivo pelo qual as idéias aqui expostas, a título de introdução, valem como indicação para ulteriores desenvolvimentos. Para o comparatista, tal como para o político e para o estadista, torna-se necessário demarcar as fronteiras de suas respectivas disciplinas, sob pena de ficar comprometida a profundidade científica exigida.

Sem tomar partido nas controvérsias em torno do tema $\left({ }^{7}\right)$, em princípio as disciplinas se distinguem por suas funções, embora considerando as mais das vezes o mesmo objeto material, que tanto poderá ser a sociedade, como o Estado, como a respectiva organização normativa. Com efeito, a Teoria do Estado considera a estrutu-

(6) Paulo Dourado de Gusmão, em sua obra mais recente, oferece uma definição de Direito Comparado como "ciência jurídica". Introdução à Ciência do Direito de A a Z, Forense, Rio, 1972.

(7) Jean Meynaud, A Ciência Política, ed. da Fundação Getúlio Vargas, Rio, 1960, pág. 18 e segs. 
ra do fenômeno Estado, seja quanto à sua forma, divisão política e administrativa, como ao seu regime político, organização e funcionamento do respectivo sistema de governo, e objetivando a explicação causal-teleológica, segundo uns, ou a compreensão dialético-valorativa, segundo outros, desse fenômeno; a Política estuda o Poder em suas diferentes manifestações, inclusive os meios de conquista do poder político, as formas do seu exercício e os fins a que se propõe, e objetivando relacionar estas manifestações, isoladamente ou em con. junto, com determinados valores historicamente vigentes na comunidade considerada. O Direito Comparado também leva em conta a estrutura do Estado e o Poder político naquilo que ambos tem de jurídico, mas com função bastante definida, qual seja, segundo René David, a unificação do Direito, a compreensão internacional e o melhor conhecimento do Direiło Nacional, mediante a sua integração na estrutura geral do pensamento dos povos $\left({ }^{8}\right)$.

- Em relação ao objeto do Direito Comparado há que distinguir ainda o Direito Comparado histórico, que considera os ordenamentos jurídicos do passado, entre si, ou relacionados ao direito atual, e o Direito Comparado dogmático, o qual tem por objeto os sistemas jurídicos atuais; a rigor somente este constitui Ciência Jurídica em sentido estrito, já que o Direito Comparado histórico pode ser considerado especialização da História do Direito; nada impede todavia que a metodologia e os objetivos sejam os mesmos, ao fazer-se referência ao passado, no Comparatismo; deve-se distinguir ainda entre - Direito Comparado puro e o aplicado, tomando como critério dessa divisão a prevalência de objetivos teórico-científicos, como a formulação de teorias jurídıcas, teses e conceitos, ou técnico-práticos, como, exemplificadamente, a elaboração de um projeto de lei.

O método do Direito Comparado tem algumas nuâncias que o fazem distinguir da metodologia concernente ao estudo de um único ordenamento jurídico histórico ou estrangeiro ou de coleções de fontes jurídicas estranhas, ou ainda de situações casuísticas; o Direito Comparado inicia com a apresentação de pontos comuns e dissemelhanças existentes, considerando-se várias ordens jurídicas; este método envolve uma contínua confrontação das normas jurídicas nacionais e estrangeiras, consideradas dentro da estrutura social que é produto da evolução histórica e do conjunto das aspirações materiais e tendências espirituais da época, no país ou no conjunito de nações tomados como ponto de referência. Assim, as regras de direito interessam ao comparatista, menos em sua expressão normativa do que na medida em que manifestam uma certa posição douttrinária.

(8) René David, op. cit. pág. 8 e segs. 
Os processos de trabalho do Direito Comparado são derivados dos próprios institutos jurídicos e dos procedimentos da técnica jurídica. As mesmas regras válidas para a distinção entre Ciência e Técnica são aplicáveis ao Direito Comparado; no plano científico, o objeto da Jurisprudência pode receber um tratameno sociológico, histórico ou dogmático-jurídico, sendo que as respectivas regras de metodologia igualmente se aplicam ao Direito Comparado, subordinadas aos fins retro indicados; assim, a pesquisa empírico-indutiva, sociológica e histórica dos fenômenos que podem ser considerados no campo do Direito, bem como, segundo outro ponto de vista $\left({ }^{9}\right)$, a consideração empírico-dialética da conduta, fornecem elementos ao Comparatismo.

3. O Direito Comparado existe em função da variedade dos sistemas jurídicos, a qual tanto pode ser verificada nas regras de direito substancial, como no espírito das normas jurídicas e nas formas de produção dessas regras; 0 mesmo instituto jurídico, pode, por conseguinie, assumir formas diferentes; a tutela, por exemplo, ora surge como um sistema de proteção ao menor, incapaz de fato, ora como uma garantia para a família, com fundamento no pressuposto de que o menor poderia fazer mau uso dos bens em detrimento de sua família, ora com ambos os aspectos, sem que tal mudança de atitude em relação ao instituto traduza uma modificação relevante no tratamento normativo que receba. Todos os ordenamentos jurídicos do Ocidente assimilaram a tese de que o direito de propriedade deve sofrer limitações legais; mas o conteúdo dessas limitações $\left({ }^{10}\right)$ é mais restrito em uns, dentro do princípio do direito individualista com função social, e mais amplo em outros, de acordo com as doutrinas coletivas, segundo as quais a propriedade é de todos, podendo não obstante estar a serviço do indivíduo como uma delegação da comunidade, subordinada porém a objetivos superiores que se identificam com os ideais coletivistas. Nos países chamados "capitalistas" o direito de propriedade assume um caráter social por influência da tradição jusnaturalista; assim, as legislações mitigaram o absolutismo que o instituto herdara do direito romano; nos países ditos "socialistas". (11) o direito de propriedade foi simplesmetne abolido, o que não obstou ao Estado atribuir a indivíduos o uso e afruição de certos

(9) Carlos Cossio, Teoria de la Verdad Jurídica, Buenos Aires, 1954.

Miguel Reale, Fundamentos do Direito, 2. a ed. São Paulo, 1972.

(10) Cfr. o meu estudo, Limitações Legais ao Direito de Propriedade, na Revista da Faculdade de Direito da Universidade Federal do Paraná, vol. 8, pág. 232, 1960.

(11) Na ciência jurídica do mundo socialista convencionou-se classificar os sistemas jurídicos segundo critérios político-ideológicos que dividem o mundo ocidental em dois blocos antagônicos; é nesse sentido que se fala em "direito burguês", aludindo ao direito dos países não socialistas. 
bens, com resultados semelhantes aos que os países capitalistas conseguiram, embora por caminhos radicalmente opostos. Outro exemplo significativo encontramos no tratamento dado pelas legislações aos direitos subjetivos; na concepção tradicional francesa os direitos subjetivos são poder da vontade; no Estado nazi-facista e no Estado soviéíico, a concepção que as leis assimilaram em matéria de direitos subjetivos atribui aos indivíduos um certo poder de coerção, no interesse de um grupo social que os ultrapassa, o "Volk" alemão ou a Internacional comunista; trata-se de uma "facultas agendi", porém que não é exercida no interesse pessoal. Outro exemplo marcante é o modo de desenvolvimento das diferentes instâncias de normatividade, conhecidas na linguagem jurídica tradicional como "fontes formais" do Direito; o Direito brasileiro é de expressão eminentemente legislativa, o Direito inglês é eminentemente consuetudinário; aqui, - "jus scriptum", lá, o "jus non scriptum"; aqui, o papel do juiz é passivo, ele interpreta as leis e as.aplica, lá, o juiz participa da criação das regras de direito segundo o princípio do precedente, consubstanciado na regra do "stare decisis". Nos sistemas jurídicos de tradição romanista, a regra de direito é concebida como um princípio normativo geral e abstrato, acima das situações concretas, formando a premissa maior de um silogismo em que a sentença se constitui $\left({ }^{12}\right)$; já no sistema jurídico da "Common Law" a norma jurídica é concebida ao nível da casuística, isio é, formando o juiz uma regra para caso concreto, conforme os precedentes, ao invés de uma regra geral $\left({ }^{13}\right)$.

Essas divergências entre os sistemas jurídicos decorrem de vários fatores, dos quais, um primeiro grupo são fatores de diversificação, outro, fatores de nivelamento. Fatores de diversificação são principalmente as diferenças de origem dos ordenamentos; a título de exemplo, faça-se referência ao individualismo extremado das tribos da floresta, em contraste com o associacionismo profundo das tribos do deserto, com repercussões nos respectivos usos e costumes e leis; tais diferenças se explicam sociologicamente pelo fato de que, na floresta, as fontes de água potável existem em abundância e são relativamente próximas umas das outras, ao passo que, nos desertos e savanas, essas fontes estão separadas por enormes distâncias; assim, a união em torno de uma fonte de água potável é condição de sobrevivência para os habitantes dessas regiões; idêntica explicação pode ser dada ao sentido da evolução dos grupos so-

(12) A teoria do silogismo jurídico tem sido criticada por autores que preconizam uma Lógica Jurídica concreta, ou Lógica do razoável, ao invés da Lógica Jurídica formal ou abstrata, tradicicnal.

(13) René David, op. cit. pág. 339. 
ciais, do nomadismo primitivo dos que viviam da caça e do pastoreio para o sedentarismo das populações dedicadas à exploração da terra, numa fase ulterior da evolução social.

Interessam sobremaneira ao comparatista os fatores de nivelamento, que podem ser reduzidos ao fenômeno das migrações jurídidicas. Estas ocorrem tanto pela imposição brutal das leis de um país invasor, como pela pacífica assimilação de um ordenamento jurídico por outro. Os exemplos de invasões são inúmeros; quando os espanhóis ocuparam a América Latina introduziram com extrema brutalidade as leis espanholas, sem nenhum respeito pelos costumes autóctones; na Áustria, o Direito nazista foi imposto no dia seguinte ao da anexação. Nem sempre porém o colonialismo determinou o nivelamento dos direitos; os franceses tentaram fazer penetrar pela força o seu direito nos países ocupados, mas fizeram-no parcialmente: o estatuto pessoal permanecia o dos povos nativos, mas em matéria de direitos reais os franceses procuraram introduzir as suas próprias concepçóes. O respeito aos costumes e tradições dos povos dominados talvez explique o relativo sucesso da colonização portuguesa na África $\left({ }^{14}\right)$.

Os exemplos mais notáveis de migração jurídica foram a expansão do Direito Romano e o trabalho de nivelamento propiciado pelo Direito Canônico.

A expansão do Direito Romano conheceu duas fases; inicialmente, em decorrência da expansão militar do Império Romano, ocorreu um nivelamento de costumes dos povos que habitavam a. Europa Ocidental; muito embora tivesse havido no início uma imposição forçada das regras do "jus gentium", a sua assimilação pelos bárbaros se explica, menos pela maneira como ocorreu a imposição - manu militare - do que pela evidente superioridade das leis de Roma e pelo fascínio que a civilização romana exercia sobre as tribos bárbaras. A segunda fase, de expansão doutrinária, conhecida como a "recepção" do Direito Romano, ocorreu muitos séculos após o desaparecimento de Roma como Estado ocidental; pela forma do seu tecnicismo, pela coerência e logicidade de seus conceitos, o Direito Romano, descoberto e estudado pelos glosadores e pós-glosadores a partir do século $\mathrm{Xl}$, utilizado inicialmente como fonte subsidiária, assumiu pouco a pouco o significado de tábua da salvação para os juízes, os quais frequentemente se viam perdidos no emaranhado de costumes locais; o envolvimento foi de tal modo crescente que, aré o advento das Codificações, o Direito Romano era o "jus commune" da Europa Ocidental.

(14) José Saraiva, op. cit. 
Em matéria de Direito de Família ocorreu nivelamento semelhante graças ao Direito Canônico; tal como na fase de expansão doutri nária do Direito Romano, mesmo em assuníos onde os juízes não eram obrigados a estatuir conforme o Direito Canônico, este se impunha "auctoritate rationis", pois as soluções canônicas eram cons:deradas mais convenientes do que as preconizadas pelas tradições locais; esta influência indireta estendeu-se aos países da Europa Oriental, favorecendo o nivelamento do antigo direito de família da Europa inteira, levando-se em conta as diferenças entre a Igreja de Bizâncio e a Igreja Romana. Tal influência não deve ser confundida com outro tipo de influência, que se pode qualificar de direta, já que, em determinados assuntos, o direito canônico se impunha de ofício, muito embora pudesse a "lex loci" estatuir diferentemente e não importando a nacionalidade do juiz.

O movimento de codificação, cujo apogeu ocorreu no século XIX, também contribuiu para a aproximação e nivelamento dos sistemas jurídicos da Europa e da América Latina, principalmente pela influência do Código de Napoleão, de 1804; no mundo da língua inglesa, a "Common Law" britânica foi assimilada pelos Estados Unidos da América durante o período colonial e expandiu-se por toda a "Commonwealth". Na América do Sul há que registrar a obra de Teixeira de Freitas, cujo Esboço, publicado em 1860 como ensaio $\left({ }^{15}\right)$, repercutiu na elaboração do Código Civil da Argentina, de 1867, o qual por sua vez, foi adotado em 1871 pelo Paraguai. Além da influência doutrinária de TEIXEIRA DE FREITAS, registra-se a influência legislativa do Código Civil do Chile, de 1885, que serviu de modelo ao Código argentino e foi adotado pela Colombia e Equador, com poucas modificações

Costuma-se referir a existência da parte geral do Código Civil Brasileiro como um exemplo de influência legislativa do Código alemão, de 1900; segundo atesta RENÉ DAVID $\left({ }^{16}\right)$, a adoção de uma parte geral para o projeto de Clóvis Bevilacqua se deve menos à influência do Bürgerliches Gesetzbuch (BGB) do que ao precedente da Consolidação das Leis Civis, de Teixeira de Freil'as, (1858), quando pela vez primeira se propôs, sob forma legislativa, uma parte geral, ○ que, não obstante, pareceu quebrar a unidade do sistema jurídico ocidental europeu, se levarmos em consideração a uniformidade que decorreu da expansão doutrinária e legislativa do Código de Napoleão.

(15) Joaquim Nabuco, Um Estadista do Império, 3.0 volume, pág. 212, nota 2, apud Clovis Bevilacqua, Código Civil Comentado, vol. I ed. de 1959, pág. 12.

(16) René David, op. cit., pág. $90, \S 66$ e nota I. 
- O fator mais permanente de nivelamento dos sistemas jurídicos é a imitação, pois o conhecimento dos sistemas estrangeiros é a comparação com as regras nacionais trazem o nivelamento. Assim, o prestígio da civilização ocidental no extremo oriente, após a $1 .^{a}$ guerra mundial, explica a europeízação dos códigos civís da China e do Japão; o mesmo sucedeu na Turquia, onde o Código Suísso foi adotado integralmente.

Há que mencionar finalmente o fenômeno das revoluções, que podem ser a um tempo fator de diversificação e fator de nivelamento. Sociologicamente, o fenômeno que se convencionou chamar de "revolução" sintetiza o desenvolvimento, dentro do grupo social, de fermentos ideológicos que possuem um poder temporário, mas intenso, de diversificação $\mathrm{O}$ grupo social, agitado por este movimento de subversão da ordem pré-estabelecida, vai, durante algum tempo, sair do circuito onde gravitam os povos vizinhos e vai encontrar-se em situação de excentricidade em relação a esta corrente geral que, sob a influência dos desejos comuns, das civilizações imitadas, das migrações jurídicas brutais, conduz à uniformidade jurídica. Mais tarde o grupo reentrará em seu concerto, a menos que sua revolução o tenha conduzido a uma nova política de hegemonia que o fará desviar-se por alguns séculos e até conduzir os grupos vizinhos a um caminho diferente.

Exemplos são o sistema da Rússia Soviética em relação ao mundo cristianizado e o sistema do $1 I^{\circ}$. Reich, o qual igualmente conduziu a Alemanha a uma posição excênírica; entretanto, a revolução será um fator de nivelamento logo que tenha a tendência a universalizar-se, como ocorreu com a Revolução Francesa, de 1789.

Por um caminho diferente pode o comparatista explicar a divergência entre os sistemas jurídicos, bastando observar o modo como as leis são propostas; existem assim duas possibilidades: primeiramente, procura-se exprimir os desejos do grupo interessado, segundo as aspirações que recebem o assentimento da maioria dos homens que compõem o grupo; a segunda possibilidade é a promoção, junto aos membros do grupo, do ideal moral ou político-ideológico que inspira uma minoria atuante, a qual realiza este ideal mediante um certo número de reformas sociais e econômicas; no primeiro caso, temos normas estáticas, também chamadas "leis naturais", nesse sentido evocado pelo comparatismo; no segundo, temos leis políticas ou revolucionárias; leis naturais ou políticas, segundo a nomenclatura ora proposta, são necessariamente divergentes; primeiro, sobre os pontos onde a influência geográfica ou ecológica é determinante, segundo, na medida em que elas se dirigem a grupos cujos graus de evolu- 
ção econômica ou cujas estruturas sociais sejam diferentes Assim, se se admite que os Estados Unidos da América e o Brasil não atingiram idêntico grau de desenvolvimento econômico e social, é evidente que as leis de direito econômico não sejam as mesmas; se a estrutura social da França é diferente da estrutura social dos países árabes, o direito sindical de ambos não poderá ser idêntico. Por conseguinte, na medida em que as leis são "naturais", isto é, expressão da maioria, a simples consideração das diferenças no grau de desenvolvimento econômico ou nas estruturas sociais explica a disparidade dos sistemas de direito positivo. Quanto às leis política ou revolucionárias, seu particularismo se demonstra ainda mais evidente, pois em sua maioria são determinadas por acidentes históricos; mas se as leis revolucionárias são sempre um fator de diversificação, no início, elas se constituem em fator de nivelamento, quando ocor-re a já mencionada tendência à expansão no circuito onde gravitam os países vizinhos, ou, mesmo não sendo países do mesmo círculo, que pelo menos possam absorver os ideais que inspiraram a revolução, os quais devem necessariamente possuir um grau muito grande de atração, podendo repetir-se o ciclo das migrações jurídicas ou manifestar-se a lei sociológica da imitação.

4. Já se observam os primeiros resultados do Direito Comparado, em matéria de uniformização dos sistemas jurídicos, pois, nos Institutos de Direito Comparado, já se pesquisa o Direito Europeu, entendido como o direito uniforme dos países do Mercado Comum Europeu, e, embora em fase embrionária, pode-se falar em Direito Latino-Americano, referindo-se às normas específicas da Associação Latino-Americana de Livre Comércio (ALALC), ou às normas comuns dos diferenies mercados comuns, como o Grupo Andino e Mercado Comum Centro-Americano.

No campo dogmático a grande contribuição do Direito Comparado à moderna Ciência do Direito é sem dúvida a classificação dos sistemas jurídicos existentes. Esta tese, o do agrupamento dos direitos positivos em famílias, é uma decorrência do fato de que, no domí nio do Direito como no das demais ciências, por trás da grande variedade dos Direitos particulares, podem ser reconhecidas categorias gerais, de número limitado, em torno das quais é possível agrupar-se os diferentes ordenamentos jurídicos. Existem elementos variáveis e elementos constantes no Direito. Sendo o Comparatismo ainda uma ciência jovem, não chegaram os comparatistas a um acordo sobre qual elemento é decisivo para agrupar os direitos em famílias. Em todos os ordenamentos jurídicos, independentemente das regras vigentes, existe todo um jogo de conceitos, de métodos de pesquisa, 
um modo peculiar de encarar o mundo, a sociedade e a justiça. Trata-se de elementos extra-normativos que dão ao Direito suas características típicas e asseguram sua unidade através de todas as variações que possam sofrer as normas; isto é de tal forma importante que a consideração pura e simples das normas jurídicas vigentes em determinado momento histórico fornecerá uma visão incompleta e evidentemente falsa do direito. Não que os elementos extra-normativos não estejam sujeitos à mesma evolução, mas que se trata de um desenvolvimento muito mais lento, ao qual se não comparam as mutações frequentes a que estão sujeitas as leis.

Infelizmente a nossa concepção de ensino jurídico se apoia sobre uma prevalência quase absoluta das normas de direito positivo, mediante a sua compartimentação entre os vários ramos do direito público e privado, prevalência que considero data venia imerecida. $O$ essencial no ensino jurídico não é apresentar as normas jurídicas vigentes, mas familiarizar o estudante com a estrutura, as categorias gerais e particulares e os conceitos de um determinado direito, considerado, no contexto formado pelo direitos da mesma família, ensinando-lhe o vocabulário desse direito; é ensinar-lhe os métodos de aplicação, interpretação e integração do direito, com a ajuda dos quais ele poderá encontrar a solução adequada aos problemas jurídicos concretos; é desenvolver no estudante uma sensibilidade própria do jurista para perceber estas soluções.

A classificação dos direitos em famílias traz uma nova distinção no Direito Comparado, a que existe entre micro-comparação e macro-comparação; na micro-comparação, consideração o direito nacional ou determinada norma jurídico-positiva, que se compara com outro direito estrangeiro; na macro-comparação, o direito é encarado esiruturalmente, como parte de uma família de direitos e se compara com conceitos idênticos, também encarados dentro de uma estrutura global, de sua respectiva família de Direito. Micro e macro-comparação revestem-se de importância especial logo que se sistematizam os procedimentos hermenêuticos, onde, ao lado das espécies de interpretação gramatical, lógica e histórica, se alinha a interpretação sistemática, pela qual a norma jurídica a ser interpretada é considerada no contexto formado pelas outras normas da mesma espécie ou no formado pelo grande sistema jurídico ao qual pertence.

5. Numa visão tão universal quanto possível das ordens jurídicas existentes atualmente, duas grandes categorias podem ser desde logo distinguidas: ordenamentos jurídicos de fundamento religioso e ordens jurídicas de fundamento civil ou secular. Enquanto a pri- 
meira categoria abrange os povos pertencentes a uma mesma comu. nidade religiosa, a segunda tem um campo de vigência puramente territorial. Os direitos confessionais dos judeus, cristãos, muçulmanos, hindus e budistas, tem validade de direito civil, principalmente nos países islamitas e do sudeste asiático, em especial quando se trata de família e sucessões; para muitos povos cristãos isto é igualmente válido em relação ao matrimônio; mas a influência européia se faz sentir no direito comercial; assim, o direito religioso, ora tem validade própria e imediata através de jurisdições religiosas, ora vale mediatamente como um direito estatal codificado.

Quanto aos direitos seculares ou não confessionais, há que distinguir o sistema romano-germanista e o anglo-americano. Ao sistema romano-germanista pertencem o Direito francês, com a imensa caudal de países que sofreram a sua influência, notadamente através do Código Civil, de 1804, em todos os estados latinos e na Ho. landa, e o grupo alemão, formado pelas duas Alemanhas, Áustria e Suíssa; ele é caracterizado pela mistura do direito ramano e canônico com numerosos costumes germânicos, assimilados pelas codificações nacionais, que mais tarde foram recepcionadas na Ásia Ocidental e Turquia. No sistema anglo-americano coexiste um direito costumeiro e jurisprudencial (common law) e um direito escrito (statutes). Um meio termo entre ambos os sistemas é constituido por alguns países da comunidade britânica e parte dos Estados Unidos da América, onde o direito romano e o de origem francesa subsistem por força da tradição, pelo menos com validade formal, já que na prática o direito do precedente venha se impondo; assim, por exemplo, Schottland, África do Sul, província de Quebec e Louisiana; como zona centro pode-se indicar os países escandinavos, que não se apoiam em nenhuma das tradições peculiares aos grandes sistemas jurídicos indicados.

A preocupação atual na dogmática comparatista é a fixação de critérios seguros de classificação dos sistemas jurídicos, não somente os da civilização do Ocidente, como os de todo o mundo. O eminenie conparatista RENE DAVID distingue cinco grandes famílias de direitos, com base na influência preponderante das respectivas civilizações: sistema ocidental, compreendendo o grupo francês e o grupo anglo-americano; sistema soviético, sistema muçulmano, sistema hindu e sistema chinês. FELIPE DE SOLÀ CAÑIZARES adota como critério a influência religiosa, distinguindo assim os sistemas ocidentais, de inspiração cristã mas cujas fontes não são constituídas pela religião, os sistemas soviéticos, de espírito ateu e anti-religioso, e os sistemas religiosos, onde as fontes são constituídas pela religião de 
maneira prevalente; assim, o direito canônico, o muçulmano, o direito hindu e o israelita.

E um assunto verdadeiramente fascinante e que oferece grandes possibilidades de desenvolvimento às vocações jurídicas autenticamente científicas e inconformadas com a relativa estagnação da Jurisprudência, em consequência do isolacionismo ainda dominante na Ciência Jurídica de cada país. 